\title{
Developing Motivating Collaborative Learning Through Participatory Simulations
}

\author{
Gustavo Zurita ${ }^{1}$, Nelson Baloian ${ }^{2}$, Felipe Baytelman ${ }^{1}$, and Antonio Farias ${ }^{1}$ \\ ${ }^{1}$ Management Control and Information Systems Department - Business School, \\ Universidad de Chile \\ gnzurita@fen.uchile.cl, fbaytelmanp@fen.uchile.cl, \\ anfariafen.uchile.cl \\ ${ }^{2}$ Computer Science Department - Engineering School. Universidad de Chile \\ nbaloian@dcc.uchile.cl
}

\begin{abstract}
Participatory simulations are collaborative group learning activities whose goals are to improve teaching and learning, increasing motivation inside the classroom by engaging the learner in games simulating a certain system they have to learn about. It has been already applied to students of primary and secondary educational levels, however there are still not experiences reported with higher level students, although there are many learning subjects to which this technique can be applied. This paper presents the implementation of a framework-like tool for supporting learning activities in a business school with undergraduate students using mobile devices over an ad-hoc network.
\end{abstract}

Keywords: Handhelds. Collaborative Learning. Participatory Simulation. Gestures. Sketches. Freehand-input based. Learning and Motivation.

\section{Introduction}

Any experienced teacher knows that without the proper motivation for students to engage in a learning experience, the otherwise best designed experiences will be unsuccessful. Dick and Carey [8] state: "Many instructors consider the motivation level of learners the most important factor in successful instruction". "Motivation is not only important because it is a necessary causal factor of learning, but because it mediates learning and is a consequence of learning as well" [20]. In other words, students who are motivated to learn will have greater success than those who are not. Participatory Simulation aims for students having "rich conceptual resources for reasoning abut and thoughtfully acting in playful and motivational spaces, and thus can more easily become highly engaged in the subject matter" [11]. It uses the availability of mobile computing devices to give each student the capability of simple data exchanges among neighboring devices [19], [4]. They enable students to act as agents in simulations in which overall patterns emerge from local decisions and information exchanges. Such simulations enable students to model and learn about several types of phenomena, [4] including those related to economics [4], [9].

Some research groups have implemented collaborative learning participatory simulations with handhelds and infrared beaming [16], and it has been found that this kind of activities 
provide various advantages for teaching and learning: (a) they introduce an effective instructional tool and have the potential to impact student learning positively across curricular topics and instructional activities [18], (b) they increase the motivation [12], [4], and (c) they generate positive effects in engagement, self-directed learning and problemsolving [12].

Although handheld's most natural data-entry mode is the stylus, most currently available handheld applications adopt the PC application approach that uses widgets instead of freehand-input-based paradigms (via touch screens) and/or sketching, [6].

This paper presents a tool for implementing collaborative learning participatory simulations, having two general research goals: (a) propose a conceptual framework for specifying and developing participative simulation applications, and (b) to determine the feasibility of using this in undergraduate curricular contexts of the simulation activities both in terms of intended and actualized learning outcomes; particularly in the management area. An instance of the framework is described. Its implementation is simple, lightweight and fully based on wirelessly interconnected handhelds with an ad-hoc network.

\section{Related Work}

A learning participatory simulation is a role-playing activity that helps to explain the coherence of complex and dynamic systems. The system maps a problem of the real world to a model with a fixed number of roles and rules. Global knowledge and patterns emerge in Participatory Simulations from local interactions among users and making decisions to understand the impact by an analysis and observation while doing and/or at the end of the activity.

Researchers are highly interested in collaborative learning participatory simulations due to these simulations appear to make very difficult ideas around 'distributed systems' and 'emergent behavior' more accessible to students [19] motivating its learning process in a playful social space [4].

Various systems using different hardware devices have been already implemented:

- A futures trading simulation described on [2] enhances the learning process of concepts such as price discovery, the open outcry trading method, trading strategies of locals and brokers, and the impact of interest rates on the treasury bond futures contract.

- Thinking Tags [1] uses small nametag sized computers that communicate with each other. It was used to tech high-school students in a simulation of virus propagation and asked them to determine the rules of the propagation [5].

- NetLogo [17] is an environment for developing of learning participatory simulations for PCs. Simulations can be re-played, analyzed and compared with previous ones. An extension called HubNet [19] supports PCs and mobile devices for input and output.

- Klopfer et al. [12] showed that the newer and more easily distributable version of Participatory Simulations on handhelds was equally as capable as the original Tag-based simulations in engaging students collaboratively in a complex problem-solving task. They feel that handhelds technology holds great promise for promoting collaborative learning as teachers struggle to find authentic ways to integrate technology into the classroom in addition to engaging and motivating students to learn science. 
- A collaborative learning participatory simulation in form of a stock exchange was designed for master's students in financial theory, using architectures based on a server and clients running on desktop PCs or laptops as well as on PDAs, [13].

- The SimCafé experiments belong to the sociological approach, aiming at validating and consolidating models [9], [4]. In this approach, participants are stakeholders and the witnesses of the emergence are domain experts, usually social scientists.

Based on the literature above mentioned, we have identified that no system has yet been proposed or implemented for handhelds in a wireless ad-hoc network using a pen-based interface as main metaphor for user interaction.

\section{Developing a Framework}

In accordance to [7] and [20] some factors, based on empirical evidence, to enhance motivation are:

- Involve the learner. Learners must be involved in the ownership of the goals, strategies and assessment of that with which they are to be engaged. The students must to fell that they are in control of their own learning.

- Respond positively to questions posed by students can enhance intrinsic motivation. Furthermore, consideration should be given to what the learner brings to the classroom: experiences, interests, and other resources.

- Options and choices about the learning environment and the various curriculum components (persons, time, content, methods, etc.) must be available.

- Simulating the reality. Whatever the expected learning outcomes, there must be a direct connection with the real world outside the classroom.

- The shifting of responsibility for learning from the teacher to the student is fundamental to both content fulfillment and learner motivation.

- Feedback and reinforcement are essential to good teaching and effective learning. When learners are given positive reinforcement, a source of motivation is tapped. Evaluation should be based on the task, rather than comparison with performance of other students.

- Collaboration among learners is a very potent way in which an individual learner forms an interpretation of the environment and develops understanding in motivational spaces of social interactions.

Collaborative learning applications based on Participative Simulations are able to meet the requirements listed above. In order to generate, design and implement them the Teacher must define learning goals, artifacts to be exchanged, behavior variables and parameters, and rules and roles for playing the simulation. In order to configure the system for a collaborative learning participatory simulation, the Teacher may setup transferable objects, their behavior parameters, rules and participant roles. Then, the teacher explains the goal of the activity to the students, also describing objects, rules and roles, and how these concepts are represented in their handhelds. Rules, roles and goals should be designed to achieve a high social interaction between students, negotiation instances, and competition to encourage an active and motivated stance [13]. A startup process must ensure students will play an active and dynamic 
role. This should be based on defining trading activities between students including Negotiation and Exchange of Objects which is supported by handhelds. These conditions depend on each particular application and may involve the following aspects: (a) type of exchange objects, (b) exchange amounts, (c) trade conditions, (d) parameters before and after the exchange, and (e) exchange objects. If students require assistance, our framework allows the teacher to wirelessly give them feedback and assessment. The teacher can (a) observe the simulation state of each participant device and (b) modify such state in order to solve the student inquiry.

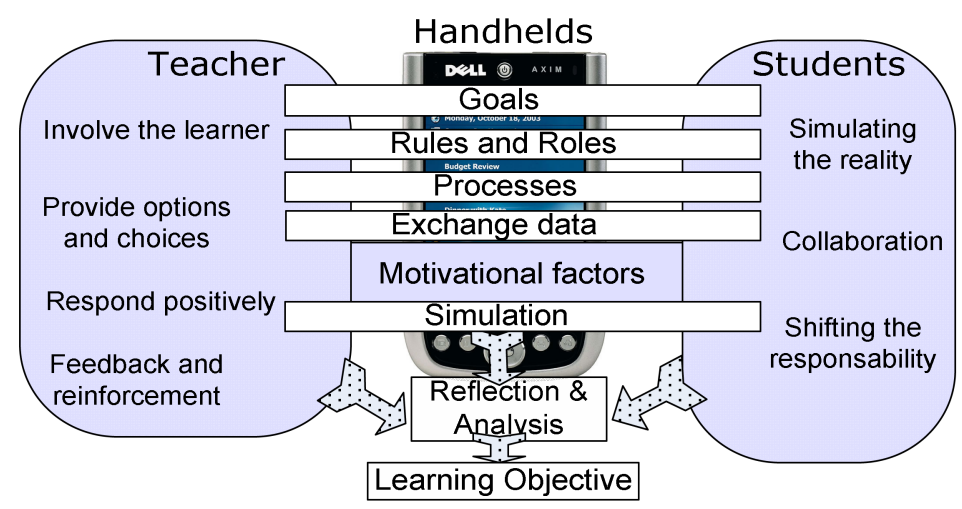

Fig. 1. Conceptual framework

Once the simulation is done, the teacher must guide students' understanding about the activity. In this way, the students will construct the learning objective together, analyzing different stages of the activity.

\section{Applications Implemented Using the Framework}

We have implemented a lightweight platform for supporting the implementation of participatory simulation applications based on the framework proposed in section 3. Using this platform we have successfully implemented two applications for the scenarios proposed on the previous section. The platform is a collection of java-classes which can be extended to implement the desired scenario in a very fast and easy way. They allow the definition of new roles, new products and the rules which will govern the simulation. It also offers implementation of interfaces for assigning roles and exchange goods, which are should be extended to implement the details of the desired application. The platform also implements all the necessary actions to discover other applications of the same class running on handhelds within the ad-hoc network and opens the necessary communication channels to exchange data between them.

\subsection{Trust Building Simulation}

This application is aimed to support the learning of concepts like reputation and trust by undergraduate students of business schools. In the simulated situation the roles of 
vendors and customers are implemented. Customers are required to maintain a certain basket with products they can acquire goods from vendors. Products have a certain lifespan which is known at the purchase moment. Customers have to replace them when they expire. The simulation assigns a random lifetime to the products around the expected one. If the product fails before the lifetime offered by the vendor customers may claim money refund or product replacement. Vendors can advertise their products freely offering a longer lifetime to attract customers or a shorter to gain customers' trust. They may refuse to refund the money or replace the product in order to make better profit. In the real world, the customers' trust to the companies is built by a repetitive interaction. A positive evaluation usually is generated when products quality is satisfactory or, even, when the company reacts appropriately after a client's complain about bad products (or services). When the simulation finishes, students must analyze these results and conclude about how clients' trust impacts the companies' profit.

a.

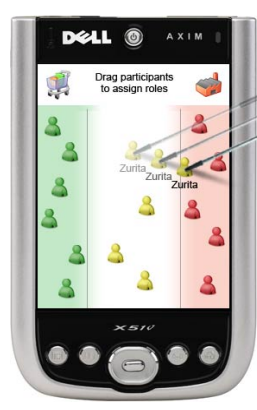

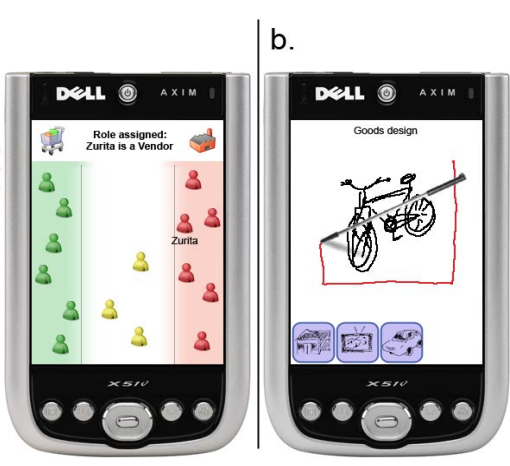

Fig. 2. a) Teacher drags a student icon into the "vendor" area to assign him a new role. b) Teacher can create new goods using free-hand drawings.

Setup phase: To assign roles to the students (customer or vendor) the teacher uses the "activity administration" mode. Students without roles are displayed in the middle of the screen over a white area. The right area of handhelds (figure 2.a) has "vendors" and left belongs to "consumers". The teacher assigns roles by drag-and-dropping the icon of a student into the desired area. Since in this application goods may be anything, they are created by the teacher by drawing a sketch and surround it by a rectangle. This will produce a "good icon", displaying an awareness of successful creation and displaying a reduced icon of the original scratch in the bottom bound of the screen. Then, additional "goods icons" may be created, as seen in Figure 2.b.

Double-clicking on a "goods icon" will open a window for defining default variables for that type of good. In this application, instance variables are "original price", "production time" and "product expected life". Once goods have been created their icons will show up in "activity administration mode". The teacher assigns goods to patricians by dragging the goods icons over the vendor icons to allow them to produce this item, or over consumer icons to ask them to acquire this item. 
Simulation phase: The simulation starts by vendors offering their products verbally and customers looking for the most convenient offer in terms of price and lifetime. Once a customer faces a vendor, they face their handhelds in order to activate the IrDA communication. This will enable the customer to receive information about the vendor's reputation and allow customer and vendor make the transaction. Figure 3 shows the three steps required to complete the transaction. When facing both handhelds the top region of the screen is converted in the negotiation area. The vendor drags the product to this area, which will appear on the buyer's negotiation area, who accepts it by dragging it to the area of products owned. The clients keep information of the reputation of each vendor with a number ranking the vendors. At the beginning it has no value. The client can set and alter this number after according to the interaction they had with vendor and also by asking other customers about the opinion they have from a vendor.

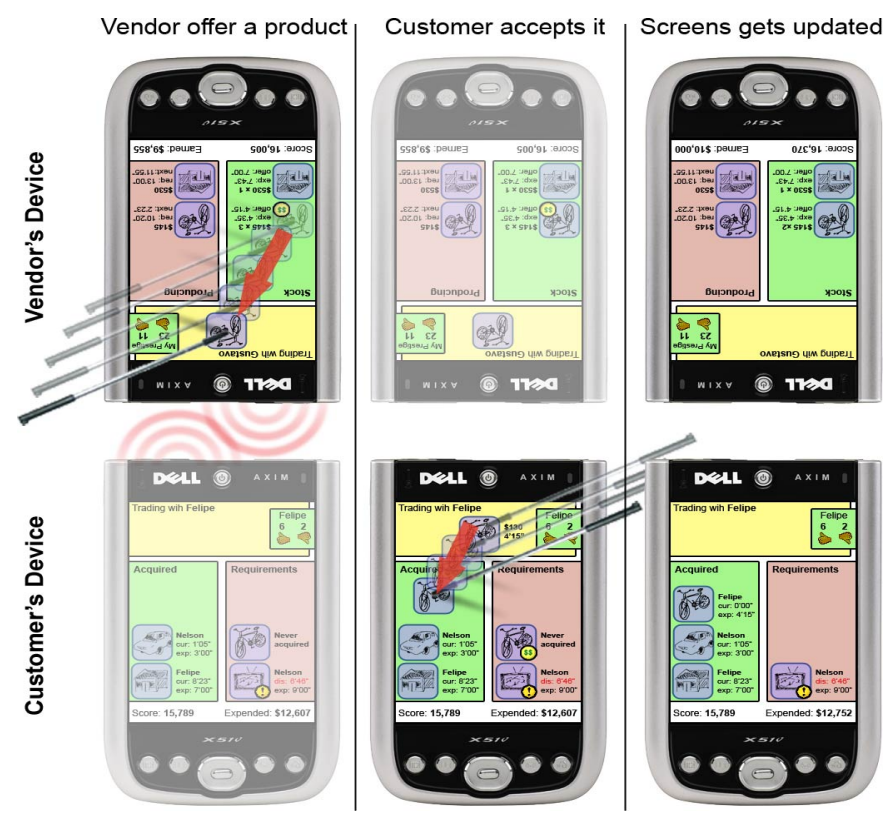

Fig. 3. Three steps in the trade process. The vendor offers a product by dragging the object, a customer accepts it, the vendor's stock and customer requirements/acquired lists get updated.

\subsection{Stock Market Simulation}

This application is about learning how offer and demand are impacted by expectations and speculations. This is learnt by simulating a stock market situation. The only role present in this simulation is the one of the investor who has to buy and sell shares trying to make profit. The teacher takes part in the simulation introducing changes in the scenario by varying the prices of the overall company. She can also participate by offering and buying shares in order to create unexpected situations simulating speculations. Students and teacher can after the simulation analyze the reactions of the simulated marked. 
Setup phase: In this scenario there is no role assignment action since all have the same one. The goods are now the shares of different companies the investors can buy and sell. The teacher creates the different shares in the same way like the previous application. Every investor receives an initial amount of shares and money.

Simulation phase: The simulation starts by letting the investors offer and buy their shares. Figure 4 a) shows the interface of the application. Students can see the amount of shares and their value, value and amount, and a small graph with the history of the values with a pull-down menu. Shares are traded using IrDA detection. Figure 4 b) shows the three steps necessary to transfer shares among students when they agree on the price and amount of the shares to be traded. When facing both handhelds, from the buyer and seller, the region at the top of the screen is converted in the trade area. The seller drags the object representing the share to this area, triggering at the buyer's handheld a dialog in order to enter the amount of shares and the money. Then the data of both is updates accordingly.
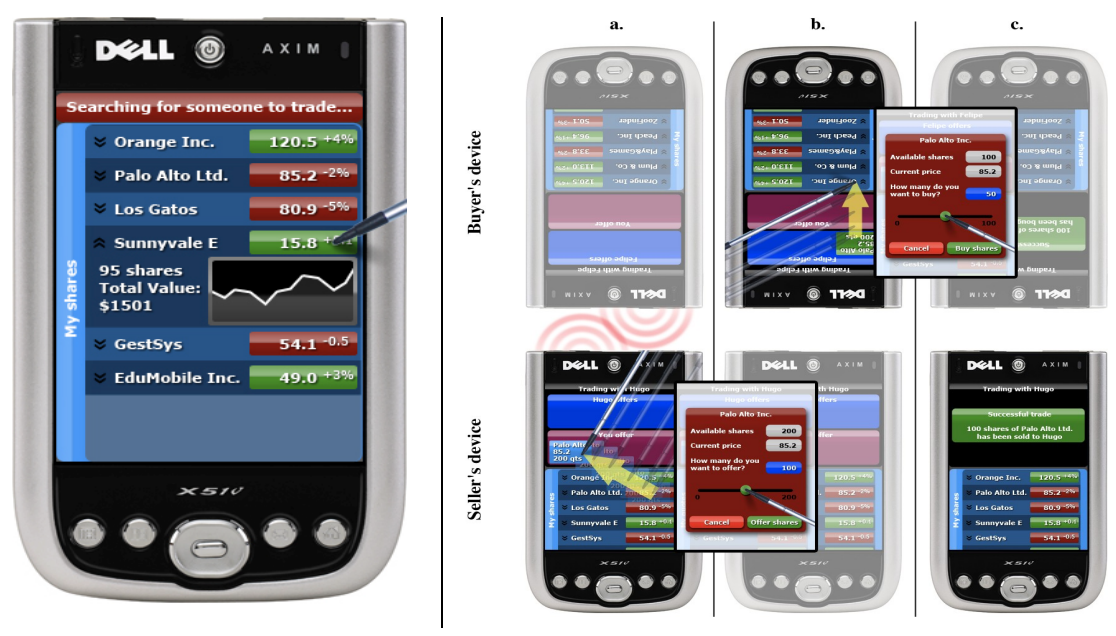

Fig. 4. a) The student's interface. b) The selling buying sequence.

\section{Discussion and Future Work}

First results of this ongoing work have shown us that mobile technology is a right approach for implementing participatory simulations. In fact, one of the most motivating factors of this kind of learning activities is the face-to-face interaction students can have among each other. Technology plays a very subtle yet important role, letting the social interaction to be at the center of the experience. On the other hand, we could experience that the platform is really a helpful tool for supporting the development of applications implementing participatory simulations and other games that are based on the exchange of artifact between the participants. The development time required for the subsequent applications can be reduced to less than $1 / 3$ of the time. We believe that the most significant contribution of the work reported here is to provide a conceptual framework for applications of collaborative learning 
participatory simulations, which is easy to adapt to many subject-matter content knowledge and undergraduate curricular integration and encouraging the adoption of learner-centered strategies. The teachers, who pre-evaluate the application, suggest that the same technologies and ideas could be used across many subject matter areas. The design of effective learning environments of our conceptual framework have included (a) learner centered environment (learners construct their own meanings), (b) knowledge-centered environment (learners connect information into coherent wholes and embedding information in a context), (c) assessment-centered environment (learner use formative and summative assessment strategies and feedback), and (d) community-centered environments (learner work in collaborative learning norms). The next phase of our investigations will develop and explore more subject-specific applications and learning and motivational measures at the student level. We are also working on developing an application which can let the teacher define a participatory simulation application without having to program a single line, only defining the roles, products and rules for exchanging products. In the current platform a language for defining these rules which could be used to generate the application is missing.

Acknowledgments. This paper was funded by Fondecyt 1050601.

\section{References}

1. Andrews, G., MacKinnon, K.A. Yoon, S.: Using "Thinking Tags" with Kindergarten Children: A Dental Health Simulation, Journal of Computer Assisted Learning, 19 (2), (2003), 209-219.

2. Alonzi, P., Lange, D., Betty, S.: An Innovative Approach in Teaching Futures: A Participatory Futures Trading Simulation, Financial Practice and Education, 10(1), (2000), 228-238.

3. Castro, B., Weingarten, K.: Towards experimental economics, J. of Political Economy, 78, (1970), 598-607.

4. Colella, V.: Participatory simulations: Building collaborative understanding through immersive dynamic modeling”. The Journal of the Learning Sciences 9, 2000, pp. 471-500.

5. Colella, V., Borovoy, R., Resnick, M.: Participatory simulations: Using computational objects to learn about dynamic Systems, Conf. on Human Factors in Computing Systems, (1998), 9 - 10.

6. Dai, G., Wang, H.: Physical Object Icons Buttons Gesture (PIBG): A new Interaction Paradigm with Pen, Proceedings of CSCWD 2004, LNCS 3168, (2005), 11-20.

7. Dev, P. (1997). Intrinsic motivation and academic achievement. Remedial \& Especial Education. $18(1)$

8. Dick, W., \& Carey, L. (1996). The systematic design of instruction (4th ed.). New York: Longman.

9. Guyot, P., Drogoul, A.: Designing multi-agent based participatory simulations, Proccedings of 5th Workshop on Aget Based Simulations, (2004), 32-37.

10. Hinckley, K., Baudisch, P., Ramos, G., Guimbretiere, F.: Design and Analysis of Delimiters for Selection-Action Pen Gesture Phrases in Scriboli, Proceeding of CHI 2005, ACM, (2005), 451-460.

11. Klopfer, E., Yoon, S., Perry, J: Using Palm Technology in Participatory Simulations of Complex Systems: A New Take on Ubiquitous and Accessible Mobile Computing, Journal of Science Education and Technology, 14(3), (2005), 285-297.

12. Klopfer, E., Yoon, S., Rivas, L.: Comparative analysis of Palm and wearable computers for Participatory Simulations, Journal of Computer Assisted Learning, 20, (2004), 347-359. 
13. Kopf, S., Scheele, N. Winschel, L., Effelsberg, W.: Improving Activity and Motivation of Students with Innovative Teaching and Learning Technologies, International Conference on Methods and Technologies for Learning (ICMTL), WIT press, (2005), 551 - 556.

14. Landay, J., Myers, B.: Sketching interfaces: Toward more human interface design, IEEE Computer, 34(3), (2001), 56-64

15. Long, A., Landay, J., Rowe, L.: PDA and gesture Use in Practice: Insights for Designers of Penbased User Interfaces, Retrieved on 2006, December, from http:// bmrc.berkeley.edu/ research/publications/1997/142/clong.html

16. Soloway, E., Norris, C., Blumenfeld, P., Fishman, R., Marx, R:: Devices are Ready-at-Hand, Communications of the ACM, 44(6), (2001), 15-20

17. Tisue, S., Wilensky, U.: NetLogo: A simple environment for modeling complexity, International Conference on Complex Systems, (2004).

18. Vahey, P., Crawford, V.: Palm Education Pioneers Program: Final Evaluation Report, SRI International, Menlo Park, CA, (2002).

19. Wilensky, U., Stroup, W.: Learning through participatory simulations: Network-based design for systems learning in Classrooms, Proceedings of CSCL'99, Mahwah, NJ, (1999), 667-676.

20. Wlodkowski, R. J. (1985). Enhancing adult motivation to learn. San Francisco: Jossey-Bass. 